\title{
The Pattern of Severe Malaria in Plateau State of Nigeria: A Five-Year Review of Severe Malaria Case-Based Surveillance Data from 2013 to 2017
}

\author{
Okokon Ita Ita ${ }^{1,}$, , Kenneth Ogar Inaku ${ }^{2}$, Anthony Achizie Iwuafor ${ }^{1}$, Ubong Anifiok Udoh ${ }^{1}$ \\ ${ }^{1}$ Department of Medical Microbiology and Parasitology, University of Calabar, Calabar, Nigeria \\ ${ }^{2}$ Department of Chemical Pathology, University of Calabar, Calabar, Nigeria
}

Email address:

itaokokonita@unical.edu.ng (O. I. Ita),keninaku@yahoo.com (K. O. Inaku), achiton@yahoo.com (A. A. Iwuafor),

ubong4dr@yahoo.com (U. A. Udoh)

${ }^{*}$ Corresponding author

\section{To cite this article:}

Okokon Ita Ita, Kenneth Ogar Inaku, Anthony Achizie Iwuafor, Ubong Anifiok Udoh. The Pattern of Severe Malaria in Plateau State of Nigeria: A Five-Year Review of Severe Malaria Case-Based Surveillance Data from 2013 to 2017. Central African Journal of Public Health. Vol. 5, No. 1, 2019, pp. 52-57. doi: 10.11648/j.cajph.20190501.18

Received: December 30, 2018; Accepted: January 21, 2019; Published: February 15, 2019

\begin{abstract}
There is a decline in the global incidence, morbidity, and mortality of malaria. However, approximately $20 \%$ of hospital admissions and $10 \%$ of hospital deaths in Nigeria have been attributed to malaria. This secondary data analysis was conducted to examine the pattern severe malaria in Plateau State in the face of declining global malaria infection. Severe malaria-specific Integrated Disease Surveillance and Response (IDRS) records of Plateau State of Nigeria over a five-year period were reviewed. A total of 38,467 cases of severe malaria were reported between January 2013 and December 2017 . The highest number of cases 14098 (36.65\%) was reported in 2016 and the least number of cases 950 (2.47\%) were reported in 2014. A total of 362 severe malaria deaths was reported within the same period with a case fatality rate (CFR) of $0.94 \%$. The highest CFR 1.43\% was recorded in 2015 while the least CFR 0.00\% was recorded in 2014. The 0-28 days age group had the highest CFR (3.13\%). The comparative monthly trend of severe malaria cases did not follow any consistent pattern during the 5 years under review. However, as of 2017, the trends of total cases per year and CFRs were on the decline. In conclusion, the overall number of cases and deaths of severe malaria is declining in Plateau State but the CFR among neonates remains high. Therefore, prevention and control efforts should be intensified in Plateau State, in order to achieve malaria elimination in the State.
\end{abstract}

Keywords: Nigeria, Malaria, Tropical Medicine

\section{Introduction}

Malaria is a protozoan infection of the red blood cells transmitted by the bite of a blood-feeding female anopheline mosquito [1]. Five species of Plasmodium have been known to infect humans: Plasmodium malariae, Plasmodium vivax, Plasmodium ovale and Plasmodium falciparum and Plasmodium knowlesi. Ninety-five percent of malaria infections in Nigeria are caused by Plasmodium falciparum and five percent by Plasmodium malariae [2]. P. falciparum is responsible for the highest morbidity and mortality attributed to malaria infection. This parasite exhibits characteristics like cytoadherence, sequestration, resetting, and aggregation, which leads to micro-circulatory obstruction in falciparum malaria [3, 4]. This obstruction in the microcirculation ultimately leads to end-organ dysfunction [5-9].

The clinical manifestations of malaria are divided into uncomplicated malaria and severe malaria. The clinical features of uncomplicated malaria are non-specific and include fever, chills and rigors headache, malaise, muscular discomfort, lack of appetite and bitter taste in the mouth [1, 10]. Severe falciparum malaria has specific diagnostic criteria $[1,10]$. These criteria are divided into clinical and laboratory criteria.

1. Clinical criteria

Prostration 
Confusion or agitation (with Glasgow Coma Scale [GCS]>11)

Coma (GCS $\leq 11$ or Blantyre Coma Scale $<3$ in children)

Respiratory distress (acidotic breathing)

Convulsions

Shock: prolonged capillary refill time ( $>2 \mathrm{~s})$, with or without systolic blood pressure $<80 \mathrm{~mm} \mathrm{Hg}$ in adults $(<70$ in children)

Pulmonary edema (confirmed radiologically)

Abnormal bleeding

Jaundice

Anuria

Repeated vomiting

hyperpyrexia (temperature $\geq 41.5^{\circ} \mathrm{C}$ )

2. Laboratory criteria

Hemoglobin $<7 \mathrm{~g} / \mathrm{dL}$ in adults, $<5 \mathrm{~g} / \mathrm{dL}$ in children

Macroscopic hemoglobinuria

Hypoglycaemia (blood glucose $<2 \cdot 2 \mathrm{mmol} / \mathrm{L}$ or $<40$ $\mathrm{mg} / \mathrm{dL}$ )

Acidosis (i.e. base deficit $>8 \mathrm{meq} / \mathrm{L}$ or plasma bicarbonate $<15 \mathrm{mmol} / \mathrm{L}$ or venous plasma lactate $>5 \mathrm{mmol} / \mathrm{L}$ )

Acute kidney injury (creatinine $>3 \mathrm{mg} / \mathrm{dL}$ or urea $>20$ $\mathrm{mmol} / \mathrm{L}$ )

Asexual parasitemia $>10 \%$ of infected red blood cells or $>250,000 / \mu \mathrm{L}$ of blood

Adults living in areas of high transmission generally come down with uncomplicated malaria, while non-immune individuals and children below three years of age are more likely to suffer from severe malaria [1].

The incidence rate of malaria declined globally between 2010 and 2017 , from 72 to 59 cases per 1000 population at risk [11]. In 2017, an estimated 219 million cases of malaria occurred worldwide compared with 239 million cases in 2010 and 217 million cases in 2016 [11]. Fifteen countries in sub-Saharan Africa and India carried almost $80 \%$ of the global malaria burden and Nigeria accounted for $25 \%$ of cases worldwide [11]. In 2017, there were an estimated 435000 deaths from malaria globally, compared with 451,000 estimated deaths in 2016, and 607000 in 2010 [11]. Children below 5 years accounted for $61 \%$ of all malaria deaths worldwide in 2017. Africa accounted for $93 \%$ of all malaria deaths in 2017 and Nigeria accounted for 19\% of all global malaria deaths [11]. All World Health Organization (WHO) Regions except the WHO Region of the Americas recorded reductions in mortality in 2017 compared with 2010. The largest declines occurred in the WHO Regions of SouthEast Asia (54\%), Africa (40\%) and the Eastern Mediterranean (10\%). About 3.2 billion people remain at risk of malaria and malaria still causes an unacceptably high number of deaths in children under the age of five [12]. In Nigeria, malaria is responsible for $60 \%$ of outpatient visits to health facilities, $30 \%$ of childhood deaths of children under 1 year and $11 \%$ of maternal deaths [13]. Approximately $20 \%$ of hospital admissions and $10 \%$ of hospital deaths in Nigeria have been attributed to malaria [14]. This secondary data analysis was carried out to epidemiologically describe severe malaria in Plateau State of Nigeria, highlight the burden of the disease in the State and make recommendations for improvements on control in the face of declining global incidence of malaria infection.

\section{Methods}

\subsection{Study Setting}

Plateau State is the twelfth largest state of Nigeria [15]. According to the 2006 census, It has a population of $3,178,712$ people [16]. It is bounded by Bauchi State to the northeast, Kaduna State to the northwest, Nasarawa State to the southwest and Taraba State to the southeast. It is located between latitude $80^{\circ} 24^{\prime} \mathrm{N}$ and longitude $80^{\circ} 32^{\prime}$ and $100^{\circ} 38^{\prime}$ east. The altitude ranges from around 1,200 meters to a peak of 1,829 meters above sea level in the Shere Hills range near Jos [17]. Years of tin mining have also left the area strewn with deep gorges and lakes which are possible breeding sites for mosquitoes. Though situated in the tropical zone, a higher altitude means that Plateau State has a near temperate climate with an average temperature of between 18 and $22^{\circ} \mathrm{C}$ [17]. Harmattan winds cause the coldest weather between December and February. The warmest temperatures usually occur in the dry season months of March and April. The mean annual rainfall varies from $131.75 \mathrm{~cm}$ (52 in) in the southern part to $146 \mathrm{~cm}$ (57 in) on the Plateau. The highest rainfall is recorded during the wet season months of July and August. The average lower temperatures Plateau State has led to a reduced incidence of some tropical diseases such as malaria [17].

\subsection{Study Design}

This was a retrospective secondary data analysis of severe malaria-specific Integrated Disease Surveillance and Response (IDRS) records.

\subsection{Study Population}

All reported severe malaria cases in the IDSR records for the period of 2013 to 2017 were reviewed. IDSR monthly epidemiological data for the years under review was obtained from the Plateau State Ministry of Health. The document contained recorded severe malaria cases from the 17 Local Government Areas of the State.

\subsection{Severe Malaria Surveillance in Nigeria}

Severe malaria surveillance in Nigeria is through the IDSR platform. Information flows from the health facilities, through the ward focal persons to the local government areas (LGA) disease surveillance and notification officers (DSNOs), to the States DSNOs, and then to the Federal Ministry of Health. Feedback goes through the opposite direction.

\subsection{IDSR Severe Malaria Case Definitions}

1. Unconfirmed severe malaria: Any patient living in an area at risk of malaria hospitalized with a severe febrile 
disease with accompanying vital organ dysfunction diagnosed clinically.

2. Confirmed Severe malaria: Any patient hospitalized with $P$. falciparum asexual parasitemia as confirmed by laboratory tests with accompanying symptoms and signs of severe disease (vital organ dysfunction) diagnosed through the laboratory.

\subsection{Laboratory Investigations}

Capillary blood samples were used in making malaria diagnosis by microscopy or rapid diagnostic test. For microscopy, thick and thin blood smears were made on microscope slides and stained with Giemsa. For rapid diagnostic testing, capillary blood was used to make the diagnosis by immunochromatographic methods following the manufacturers' instructions.

\subsection{Data Management}

Relevant data from the IDSR line list were sorted, extracted, and cleaned. These included the number of cases, number of deaths and location. The data were analyzed for frequencies and proportions.

\section{Results}

A total of 38, 467 cases of severe malaria were reported between January 2013 and December 2017. The highest number of cases 14098 (36.65\%) were reported in 2016, followed by $11106(28.87 \%)$ in 2017 . The least number of cases $950(2.47 \%)$ were reported in 2014 (table 1). A total of 362 severe malaria deaths were reported within the same period with a case fatality rate (CFR) of $0.94 \%$. The highest CFR $1.43 \%$ was recorded in 2015 , followed by $1.00 \%$ in 2016. The least CFR $0.00 \%$ was recorded in 2014 (table 1). The highest CFR according to age was $3.13 \%$ among those aged 0-28 days (neonates) while the least CFR 0.05\% was among those older than 40 years (table 2).

The comparative monthly trend of severe malaria cases did not follow any consistent pattern during the 5 years under review. The highest number of cases occurred in March 2016, while no cases were reported in November and December of 2013 and May and October of 2014. (figure 1). However, the trends of total cases per year and CFRs followed the same pattern. The cases and CFRs declined to their lowest levels in 2014. This was followed by a sharp increase with the CFR peaking in 2015 and the number of cases peaking in 2016. As of 2017, both were on a downward trend (figure 2). Wase Local Government Area had the least number of reported cases within this five-year period, followed by Jos East and Mikang. Riyom Local Government Area had the highest number of cases, followed by Shendam and Langtang North in descending order (figure 3 ).

Table 1. Number of cases, deaths and case fatality rates by years for severe malaria in Plateau State, Nigeria, from January 2013 to December 2017.

\begin{tabular}{lllll}
\hline Year & Total number of cases & Percent (\%) & Deaths & Case fatality rate (\%) \\
\hline 2013 & 5,048 & 13.12 & 41 & 0.81 \\
2014 & 950 & 2.47 & 0 & 104 \\
2015 & 7,265 & 18.89 & 141 & 1.43 \\
2016 & 14,098 & 36.65 & 76 & 1.00 \\
2017 & 11,106 & 28.87 & 0.00 & \\
Total & 38,467 & 100.00 & 362 & 0.94 \\
\hline
\end{tabular}

Table 2. Distribution of cases, deaths, and CFR of severe malaria by age groups in Plateau State, Nigeria, from January 2013 to December 2017.

\begin{tabular}{lllll}
\hline Age groups & Cases & Percent (\%) & Deaths & Case fatality rate (\%) \\
\hline 0-28 days & 894 & 2.32 & 28 & 64 \\
1-11 months & 3978 & 10.34 & 102 & 1.61 \\
12-59 months & 7909 & 20.56 & 107 & 1.29 \\
$5-9$ years & 8546 & 22.22 & 49 & 1.25 \\
$10-19$ years & 6918 & 17.98 & 10 & 0.71 \\
20-40 years & 6314 & 16.41 & 2 & 0.16 \\
$>40$ years & 3908 & 10.16 & 362 & 0.05 \\
Total & 38467 & 100.00 & & 0.94 \\
\hline
\end{tabular}

\section{Discussion}

This study found the case fatality rate of severe malaria to be highest among neonates.

Although it is well known that malaria is an important cause of infant morbidity and mortality in sub-Saharan Africa, neonatal malaria was considered a rare condition [18]. It was believed that the fetal hemoglobin provided some protection to the newborn against malaria [19]. This, however, is not the case as studies across Africa including Nigeria have shown neonatal malaria rates ranging from 0 to $54.2 \%$ [18-21].
Whether the neonatal mortality in this review was due to severe malaria alone could not be ascertained. In any case, there is a need to intensify the administration of intermittent presumptive treatment of malaria in pregnancy and the use of long-lasting insecticide-treated bed nets among pregnant women and newborn babies. This will help in reducing cases of neonatal deaths that are caused by severe malaria in Plateau State.

The total number of cases and the CFRs of severe malaria in Plateau State has been on the downward trend since 2015 and 206 respectively. This is in keeping with the global downward trend in the morbidity and mortality of malaria in 
Africa [11]. In 2008, the National Malaria Control Programme in Nigeria adopted the goal of reducing to $50 \%$ the country's malaria burden by 2013 by achieving at least $80 \%$ coverage of long-lasting impregnated mosquito nets, $20 \%$ of houses in targeted areas receiving indoor residual spraying and treatment with two doses of intermittent preventative therapy (IPT) for $100 \%$ of pregnant women who visit antenatal care clinics [22]. These efforts may have contributed to these downward trends.

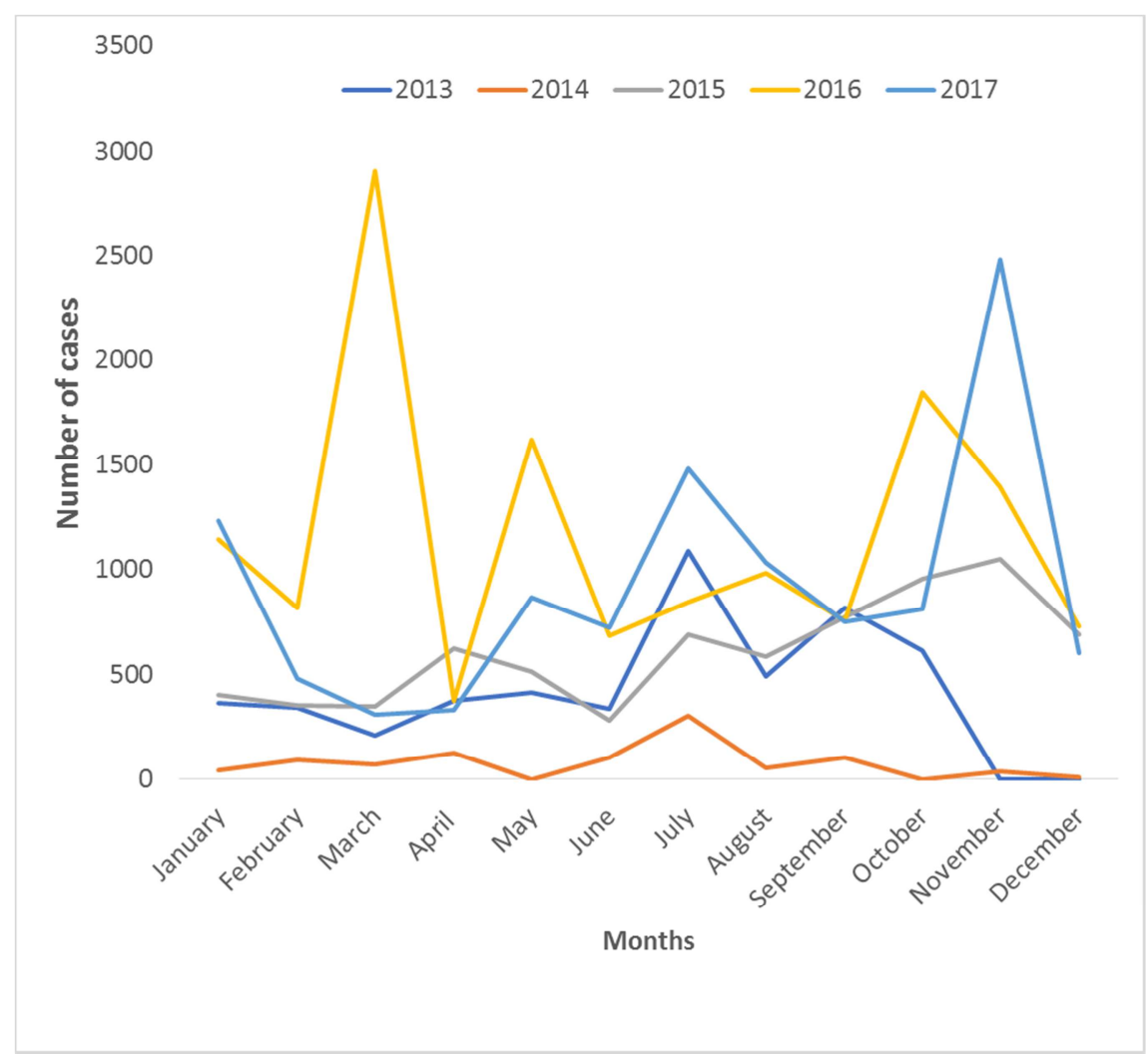

Figure 1. Comparative monthly trend of severe malaria cases in Plateau State from 2013 to 2017.

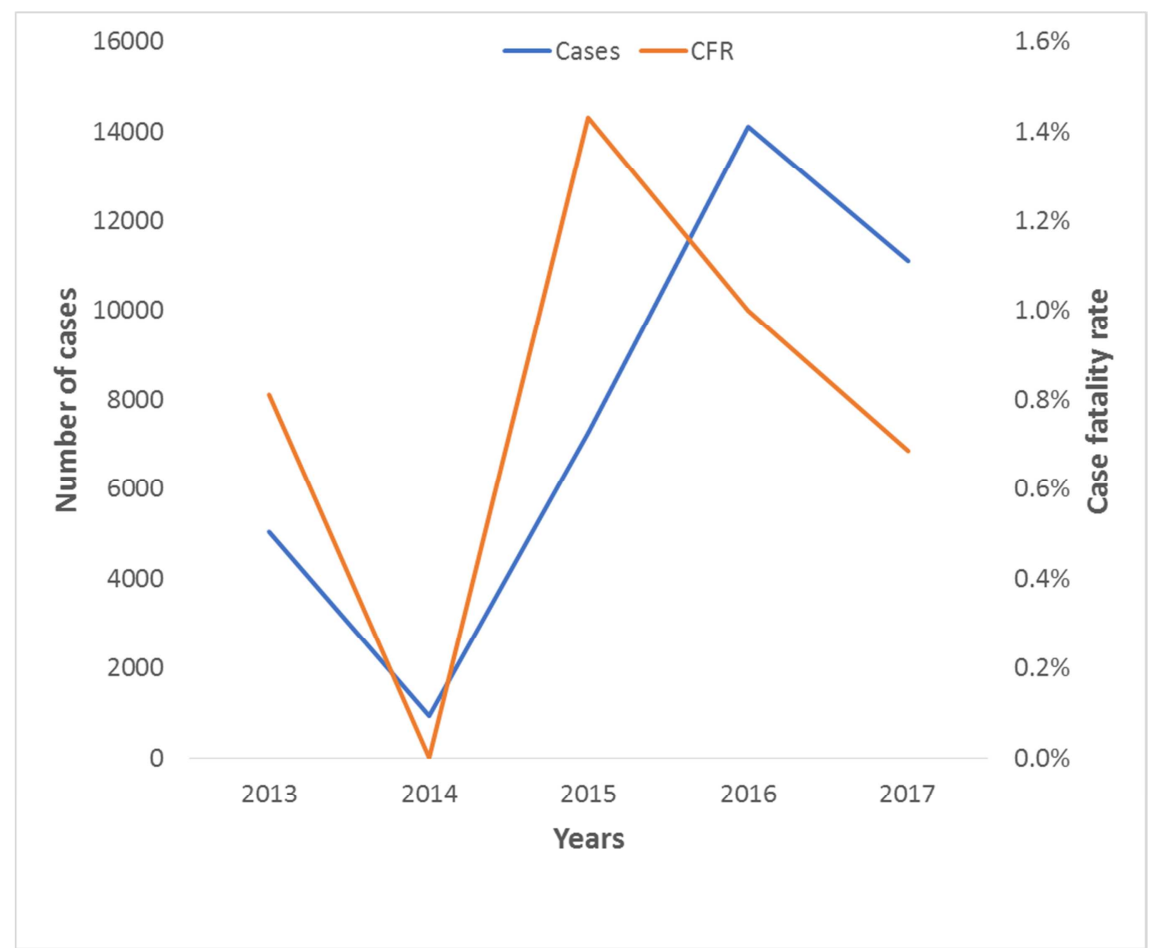

Figure 2. Yearly trend of cases and case fatality rates of severe malaria in Plateau State from 2013 to 2017. 


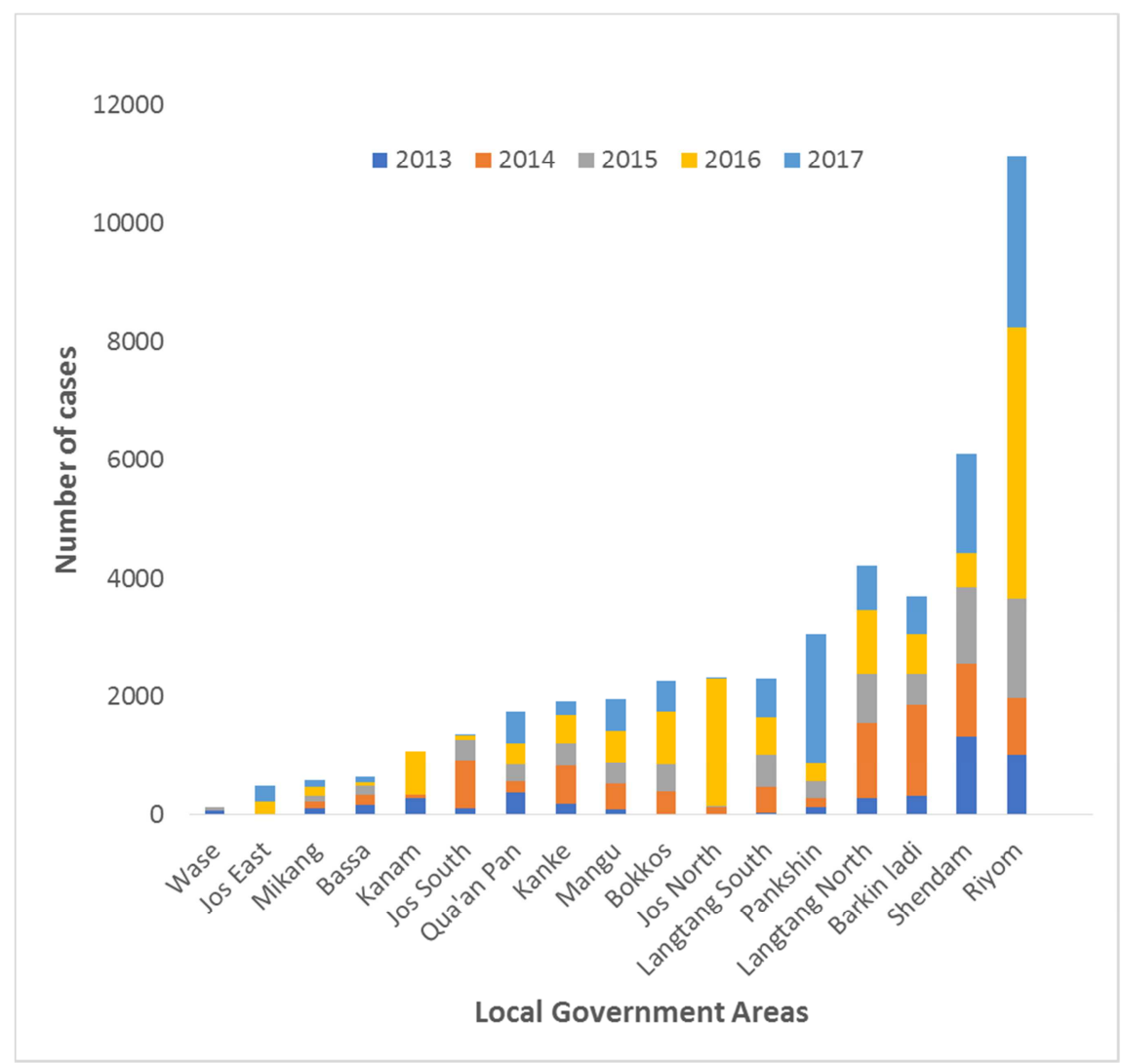

Figure 3. Distribution of severe malaria cases by Local Government Areas in Plateau State from January 2013 to December 2016.

\section{Conclusion}

Severe malaria remains a major cause of childhood mortality in Plateau State. Though the overall number of cases and deaths are declining, the CFR among neonates remains high. Case-based surveillance provided insight into understanding the epidemiology of severe malaria in Plateau State.

\section{Recommendations}

Currently, Nigeria is implementing its malaria elimination programme. Therefore, prevention and control efforts should be intensified and cased based surveillance of malaria should be enhanced in Plateau State, in order to achieve the elimination of malaria in Nigeria.

\section{References}

[1] White NJ. Malaria. In: CC, Gordon IA, editor. Manson's Tropical Diseases. 22nd ed. Philadelphia, PA: WB Saunders; 2009. p. 1209-81.

[2] Okwa O, Akinmolayan FI, Carter V, Hurd H. Transmission Dynamics of Malaria in Four Selected Ecological Zones of Nigeria in the Rainy Season. Ann AfricanMedicine [Internet]. 2009; 8 (1): 1-9. Available from: http://www.bioline.org.br/pdf?am09001.

[3] Magallón-Tejada A, Machevo S, Cisteró P, Lavstsen T, Aide
$\mathrm{P}$, Rubio $\mathrm{M}$, et al. Cytoadhesion to $\mathrm{gClqR}$ through Plasmodium falciparum Erythrocyte Membrane Protein 1 in Severe Malaria. PLOS Pathog [Internet]. 2016 Nov 11; 12 (11): e1006011. Available from: https: //doi.org/10.1371/journal.ppat.1006011.

[4] Vigan-Womas I, Guillotte M, Le Scanf C, Igonet S, Petres S, Juillerat A, et al. An in vivo and in vitro model of Plasmodium falciparum rosetting and autoagglutination mediated by varO, a group A var gene encoding a frequent serotype. Infect Immun. 2008; 76 (12): 5565-80.

[5] Autino B, Corbett Y, Castelli F, Taramelli D. Pathogenesis of malaria in tissues and blood. Mediterr J Hematol Infect Dis. 2012;4(1).

[6] Silva LS, Silva-Filho JL, Caruso-Neves C, Pinheiro AAS. New Concepts in Malaria Pathogenesis: The Role of the Renin-Angiotensin System. Front Cell Infect Microbiol [Internet]. 2016;5 (January): 5-10. Available from: http: //journal.frontiersin.org/Article/10.3389/fcimb.2015.00103/ab stract

[7] Moncunill G, Mayor A, Jiménez A, Nhabomba A, Puyol L, Manaca MN, et al. Cytokine and Antibody Responses to Plasmodium falciparum in Naïve Individuals during a First Malaria Episode: Effect of Age and Malaria Exposure. PLoS One. 2013; 8 (2).

[8] Cholera R, Brittain NJ, Gillrie MR, Lopera-Mesa TM, Diakite SAS, Arie T, et al. Impaired cytoadherence of Plasmodium falciparum-infected erythrocytes containing sickle hemoglobin. Proc Natl Acad Sci [Internet]. 2008; 105 (3): 991-6. Available from: http://www.pnas.org/cgi/doi/10.1073/pnas.0711401105 
[9] Aponte JJ, Menendez C, Schellenberg D, Kahigwa E, Mshinda $\mathrm{H}$, Vountasou $\mathrm{P}$, et al. Age interactions in the development of naturally acquired immunity to Plasmodium falciparum and its clinical presentation. PLoS Med. 2007; 4 (7): 1259-67.

[10] Ashley EA, Pyae Phyo A, Woodrow CJ. Malaria. Lancet. 2018; 391 (10130): 1608-21.

[11] World Health Organization. World Malaria Report 2017. 2018.

[12] World Health Organization. Global Health Observatory (GHO) data - malaria. [Internet]. 2018 [cited 2018 Dec 6]. Available from: http://www.who.int/gho/malaria/en/.

[13] Nigerian Federal Ministry of Health. National Malaria Control Programme. [Internet]. 2014 [cited 2018 Dec 6]. Available from: http://nmcp.gov.ng/.

[14] Okeke T, Uzochukwu B, Okafor H. An in-depth study of patent medicine sellers' perspectives on malaria in a rural Nigerian community. Malar J. 2006; 5: 97.

[15] The Editors of Encyclopaedia Britannica. Plateau state, Nigeria. [Internet]. 2018 [cited 2018 Dec 6]. Available from: https://www.britannica.com/place/Plateau-state-Nigeria.

[16] National Bureau of Statistics. Federal Republic of Nigeria 2006 Population Census [Internet]. 2006. Available from: www.nigerianstat.gov.ng.
[17] Plateau State Government. Plateau State [Internet]. 2018 [cited 2018 Dec 6]. Available from: https: //www.plateaustate.gov.ng/page/at-a-glance.

[18] Runsewe-Abiodun IT, Ogunfowora OB, Fetuga BM. Neonatal malaria in Nigeria - A 2-year review. BMC Pediatr. 2006; 6: $1-5$.

[19] Shear HL, Grinberg L, Gilman J, Fabry ME, Stamatoyannopoulos G, Daniel E, et al. Malaria by a Novel Mechanism by a Novel Mechanism. Med Hyg (Geneve). 2012; 92 (7): 2520-6.

[20] Uneke CJ. Congenital malaria: An overview. Tanzan J Health Res. 2011; 13 (3): 264-80.

[21] Rupa DKM. Clinical Presentation and Management of Neonatal Malaria: A Review. Malar Chemother Control Elimin [Internet]. 2014;03(02). Available from: https://www.omicsonline.com/open-access/clinicalpresentation-and-management-of-neonatal-malaria-a-review2090-2778.1000126.php?aid=37135.

[22] Dawaki S, Al-Mekhlafi HM, Ithoi I, Ibrahim J, Atroosh WM, Abdulsalam AM, et al. Is Nigeria winning the battle against malaria? Prevalence, risk factors and KAP assessment among Hausa communities in Kano State. Malar J. 2016; 15 (1): 1-14. 